\title{
ECONOMIA CIRCULAR APLICADA À LIMPEZA DE JAZIDAS DE ROCHAS ORNAMENTAIS DO BRASIL
}

\author{
João Pedro do Carmo Costa Santos ${ }^{1}$; Vitório Donato² \\ ${ }^{1}$ Centro Universitário Senai Cimatec; Salvador/Bahia; j.costa_ba@hotmail.com; \\ ${ }^{2}$ Centro Universitário Senai Cimatec; Salvador/Bahia;
}

Resumo: A extração de rochas ornamentais é uma prática rentável às empresas de beneficiamento e exploração deste mineral em todo o mundo, porém, é uma prática que ao longo dos anos de exploração tem gerado centenas de toneladas de estoques remanescentes de rochas, distribuídos indevidamente nas jazidas, causando impactos ambientais negativos para todas as regiões onde ocorre extração, dificultando a limpeza posterior das áreas. Este artigo propõe uma rota tecnológica utilizando o conceito de economia circular para realizar o processo de reutilização e renovação do material não utilizado após a extração dos blocos de rocha, trazendo um novo conceito estratégico para promover o crescimento econômico e o aumento do consumo dos recursos que não são aproveitados e redução dos impactos negativos do processo de extração e beneficiamento de rocha ornamental.

Palavras-Chave: Economia Circular; Rocha Ornamental; Estoque Remanescente.

\section{CIRCULAR ECONOMY APPLIED TO CLEANING QUARRIES OF ORNAMENTAL ROCKS OF BRAZIL}

\begin{abstract}
The extraction of ornamental stones is a profitable practice for the beneficiation and exploration companies of this mineral worldwide, however, it is a practice that over the years of exploration has generated hundreds of tons of remaining rock stocks, improperly distributed in the quarries, causing negative environmental impacts for all regions where extraction occurs, making it difficult to clean the areas later. This paper proposes a technological route using the concept of circular economy to perform the process of reuse and renewal of unused material after the extraction of rock blocks, bringing a new strategic concept to promote economic growth and increased consumption of resources that unused and reducing the negative impacts of the process of extraction and processing of ornamental rock.
\end{abstract}

Keywords: Circular Economy; Ornamental Rocks; Remaining Stocks Reuse. 


\section{INTRODUÇÃO}

As atividades de exploração das jazidas e o beneficiamento de rochas ornamentais no Brasil se desenvolveu ao longo dos anos de forma desordenada e com diferentes padrões de extração, conforme localização das jazidas do país. Os parâmetros de qualidade utilizados para selecionar o bloco extraído, como próprio para comercialização, geram grandes volumes de rejeitos nas proximidades das lavras. Além dos rejeitos gerados durante o processo de extração, existem rejeitos gerados no processo de beneficiamento nas serrarias. (APOLINÁRIO et al., 2013 [1]).

O aproveitamento dos resíduos produzidos na cadeia produtiva de rochas ornamentais deve ser planejado junto com o processo de exploração do minério, tendo em vista o grande volume de perdas de material, tanto na etapa da extração quanto na etapa do beneficiamento. Somando estas duas parcelas de perdas, chegasse a valores da ordem de $75 \%$, na média, apresentando um aproveitamento médio que varia de 15 a 25\% de todo o material minerado. (MOURA et al., 2002 [2]).

O estudo da aplicação da economia circular, deve levar em conta a recuperação dos resíduos produzidos, onde o retorno financeiro pode ser compensador economicamente, além de gerar emprego e renda, e de uma maior harmonização com as comunidades vizinhas as regiões produtoras além de capacitar os cidadãos, trazendo benefícios para os envolvidos.

A necessidade de dar uma destinação econômica aos rejeitos gerados pelas atividades da cadeia produtiva das pedras ornamentais, foi determinante para a elaboração deste estudo, fazendo o link entre a economia circular, sustentabilidade e reutilização de materiais remanescentes nas jazidas com a geração de renda para as populações que são impactadas com a extração e beneficiamento das rochas ornamentais, onde, em sua maioria, são regiões que tem a exploração das rochas como maior fonte de renda.

Este estudo tem por objetivo criar uma rota tecnológica para gerenciar os estoques remanescentes de rochas ornamentais, dando a estas uma destinação econômica, gerando ocupação e renda, ao tempo em que atenua os impactos ambientais gerados desde com a sua extração. Para definição desta rota foi empregada o modelo de resistência aos fluxos logísticos, que permitirá identificar a rota mais adequada, as barreiras envolvidas e o custo de operacionalização.

\subsection{ECONOMIA CIRCULAR}

O sistema de economia circular vem ganhando cada vez mais credibilidade e força para substituir o modelo convencional de produção, que é o modelo linear de produção, que tem como base "extrair, produzir, consumir e descartar". A tendência deste século para as grandes e pequenas empresas tem sido desenvolver uma consciência ecológica com a certeza que os recursos naturais são esgotáveis e que devem ser reaproveitados.

A economia circular é a metodologia que traz uma atraente alternativa à economia linear, pois tem como base o conceito de "reduzir a exploração, produzir, consumir conscientemente, reciclar e reutilizar", mas trazendo o modelo sustentável aplicado à realidade da produção e comercialização na atualidade (Lacy, 2015 [3]). O 


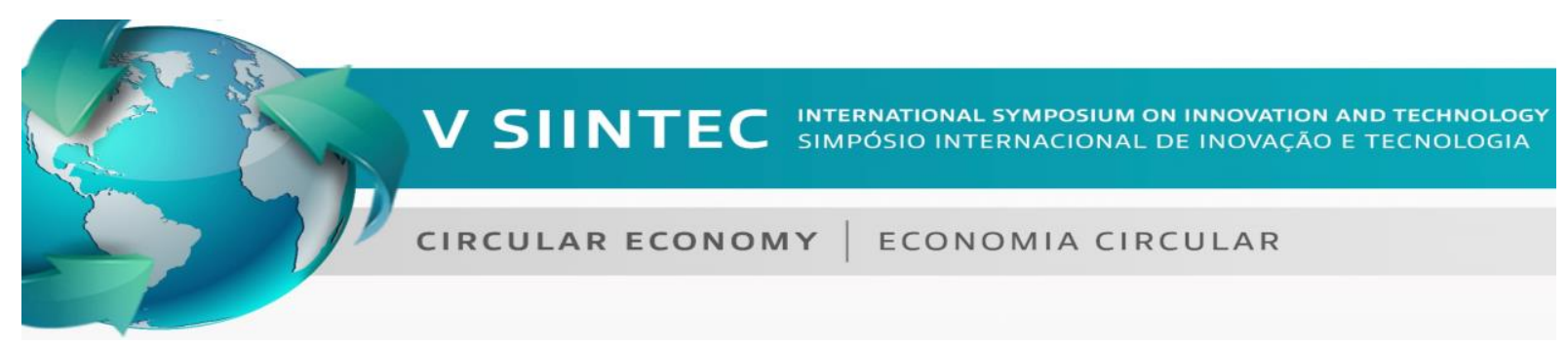

modelo segue a ideia de utilização racional dos recursos, onde tem a proposta de desconstruir o conceito de descarte de resíduos, com a implantação e melhoria de sistemas que incluam e desenvolvam materiais que possam ser inteiramente recuperados e reutilizados e no caso da mineração, evitando a extração de novos minerais.

O conceito sendo aplicado no processo de extração de blocos de rocha no Brasil, traz além de benefícios ambientais, benefícios econômicos e sociais para as regiões de influência. Uma economia circular busca reconstruir o capital, seja ele financeiro, manufaturado, humano, social ou natural. Isto garante fluxos aprimorados de bens e serviços. (Stahel, 1982, 2010 [4]).

Para o funcionamento da rota tecnológica proposta, é de grande importância a união entre os produtores locais para a mudança do cenário atual, para isso, será criada uma associação na região, que será responsável pela gestão dos materiais remanescentes gerados pelas jazidas. Sendo estruturado a construção das unidades produtivas, segundo mapeamento realizado do material produzido, visando ações de cunho socioeconômico para a região, atraindo investidores para iniciativa e financiamento de materiais para a produção. O funcionamento da rota tecnológica está descrito na imagem a seguir:

Figura 1. Rota tecnológica proposta

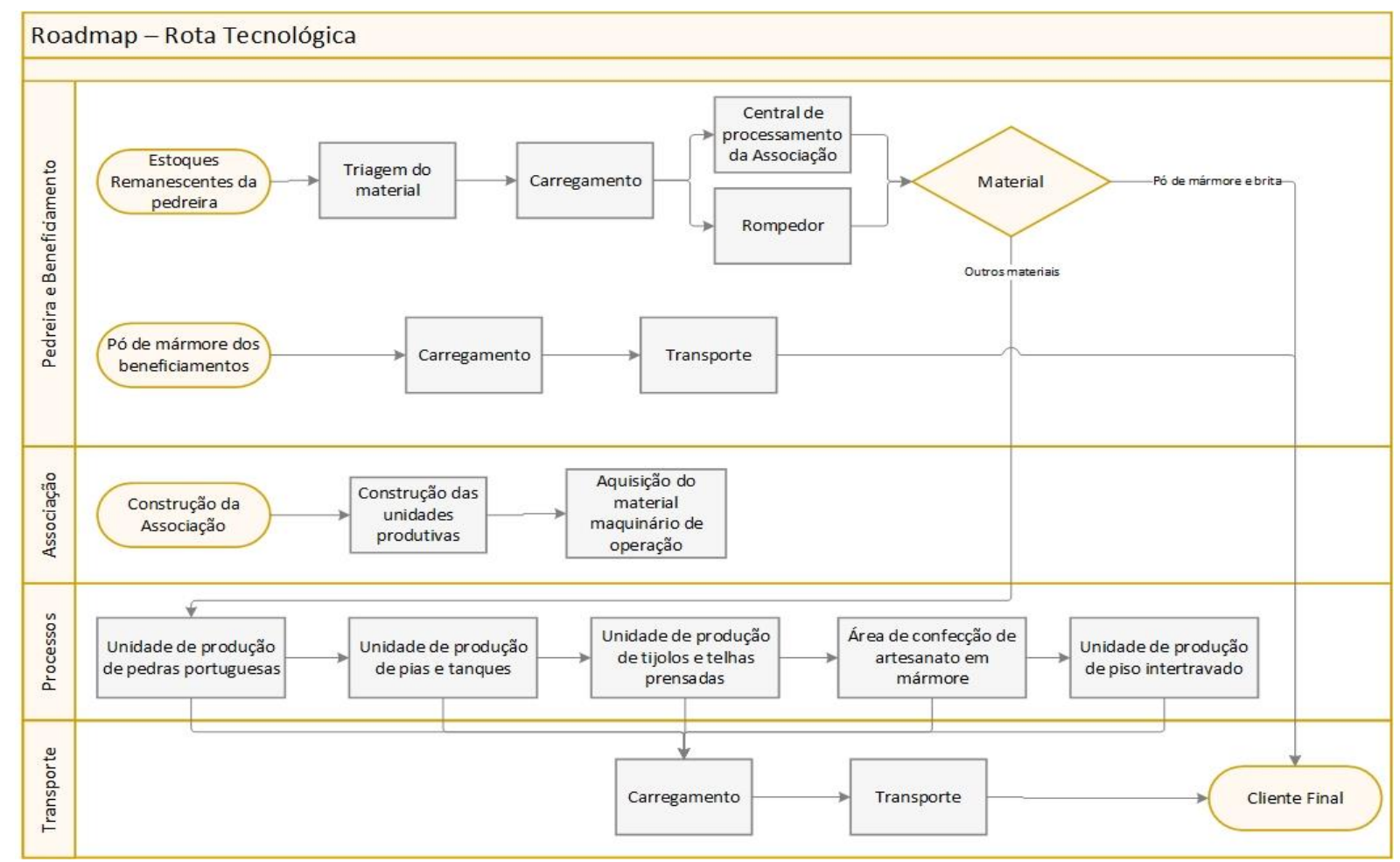

Fonte: Autor, 2019

A rota tecnológica proposta contempla a coleta e reaproveitamento do material remanescentes das jazidas sendo uma iniciativa de longo prazo com definição estratégica para uma ação de envio a centrais de processamento que serão 
responsáveis pelos processos de britagem e peneiramento. Estas centrais farão a redução das dimensões dos blocos de rocha e realizarão o carregamento das carretas nas jazidas com destino, o cliente final, conforme a demanda.

A associação gerenciadora funcionará com a premissa de não poder produzir materiais que tem o potencial de competir com os produtores de rocha ornamental da região, validando o trabalho da pesquisa de benchmark sobre a reutilização do material.

\subsection{UNIDADES PRODUTIVAS}

A associação irá gerenciar os estoques remanescentes, onde serão implantadas unidades produtivas para realizar 0 reaproveitamento $e$ a comercialização do material remanescente. Essas unidades produtivas tem o objetivo de qualificar a mão de obra local, realizar cursos de artesanato e gerar renda com o material produzido, ajudando na economia circular da região, além de ser uma ferramenta gerencial para limpeza das jazidas, pois conforme a demanda do material se desenvolve, maior a quantidade que será reutilizada.

Essas unidades produtivas foram idealizadas por meio da aplicação da metodologia roadmap e posteriormente foram realizadas pesquisas com as empresas produtores da região e levantamento dos estoques remanescentes de rocha ornamental em outras regiões do Brasil e do mundo. Os produtos a serem produzidos nas unidades produtivas propostas foram:

- Unidade de produção de pias e tanques (uso de material granulado);

- Unidade de produção de peças artesanais (uso de seixos de rochas);

- Unidade de produção de pedra portuguesa (uso de seixos de rochas);

- Unidade de produção de piso Intertravado (uso de pó de rochas);

- Unidade de produção de tijolo e telhas prensadas (uso de material granulado).

\section{METODOLOGIA}

Para o desenvolvimento do estudo e da análise foi utilizada a metodologia da roadmap, o processo de definição de uma Rota Tecnológica - TRM que consiste no mapeamento a partir da discussão entre representantes das diferentes perspectivas relacionadas às camadas utilizadas (PHAAL et al., 2004b [5]). A característica essencial do Mapeamento de uma Rota Tecnológica -TRM é o uso de uma estrutura gráfica que represente múltiplas camadas, interdependentes ao longo do tempo (PHAAL \& MULLER, 2008 [6]). Essas camadas interligadas devem ser tais que permitam a representação do desenvolvimento de tecnologia motivados tanto por demandas do mercado (market-pull) quanto por capacidades da organização (technology-push), resultando em um mapa de rotas tecnológicas (PHAAL et al., 2004b [5]).

Para definição das camadas tecnológicas foi utilizado o modelo de análise das resistências aos fluxos logísticos, que foi organizada a partir de quatro dimensões consideradas importantes para caracterizar os impedimentos aos fluxos logísticos 
(DONATO \& PASSOS, 2014 [7]). Segundo Donato \& Passos 2014, as dimensões definidas para a análise das resistências são a infraestrutura, os custos logísticos, barreiras e os impactos ambientais provocados pelos fluxos logísticos. As dimensões de resistência foram desdobradas em fatores, conforme se observa na tabela 1. Os fatores de resistência quanto à infraestrutura referem-se à possibilidade de ocorrência de conflito legal; à posição geográfica da empresa; à disponibilidade de mão de obra e ao custo de implantação e manutenção de cada unidade.

Já os fatores referentes à dimensão dos custos logísticos, referem-se, em geral, aos impedimentos de caráter econômico. Os fatores escolhidos para compor esta dimensão compreendem custo por viagem; idade da frota; vulnerabilidade da carga; e o consumo de pneus. Quanto aos fatores inerentes às barreiras a implantação, foram escolhidos os seguintes: o número de pontos de coleta; o tempo parado por ponto de entrega; o número de entregas por dia; e o congestionamento das rotas. Finalmente, o os fatores referentes à dimensão dos impactos causados ao meio ambiente são pela emissão de CO2; impactos da atividade identificados e percebidos durante a circulação da frota e a proximidade da atividade de distribuição em relação a áreas protegidas.

Tabela 1. Descrição dos processos propostos.

\begin{tabular}{|c|c|c|c|c|c|}
\hline Fatores & \multirow{2}{*}{ Infraestrutura } & \multicolumn{2}{|l|}{ Impactos } & \multirow{2}{*}{ Barreiras } & \multirow[t]{2}{*}{ Custo } \\
\hline Rota Proposta & & Positivo & Negativo & & \\
\hline $\begin{array}{l}\text { ROTAS } \\
\text { TECNOLÓGICAS } \\
\text { PROPOSTAS }\end{array}$ & $\begin{array}{l}\text { Descrição dos } \\
\text { processos } \\
\text { infraestrutura } \\
\left(\text { Peso de } 0-5^{\star}\right) . \\
\text { *: Quanto maior o peso, } \\
\text { maior a resistência ao } \\
\text { fluxo, isto é, maior } \\
\text { impacto negativo será a } \\
\text { variável na referente rota. }\end{array}$ & $\begin{array}{l}\text { Descrição dos } \\
\text { impactos } \\
\text { positivos das } \\
\text { rotas + (peso*) }\end{array}$ & $\begin{array}{l}\text { Descrição } \\
\text { dos impactos } \\
\text { negativos das } \\
\text { rotas } \\
(\text { peso*) }\end{array}$ & $\begin{array}{ll}\text { Descrição } & \text { das } \\
\text { barreiras } & \\
\text { encontradas } & \\
\text { viabilidade a a de } \\
\text { execução das rotas } \\
+(\text { peso* }\end{array}$ & $\begin{array}{l}\text { Descrição dos } \\
\text { custos para a } \\
\text { implantação das } \\
\text { rotas + (peso*) }\end{array}$ \\
\hline
\end{tabular}

Fonte: Autor, 2019

Assim, baseado na lógica Fuzzy (Nicoleti, 2006 [8]), foi elaborado um formulário onde são desdobrados os fatores de resistência com o foco no reaproveitamento e na distribuição dos estoques remanescentes. Estes fatores abordam: a infraestrutura, impactos (positivos e negativos), barreiras de implantação e custos. Essas dimensões convergem para uma matriz que calcula o índice de resistência, conforme a pontuação obtida escalona os dados.

\section{RESULTADOS E DISCUSSÃO}

A partir da aplicação da lógica Fuzzy (Nicoleti, 2006 [8]), foram pontuadas todas as unidades produtivas propostas para o reaproveitamento do material. Estas unidades foram igualmente pontuadas conforme a necessidade geral de equipamentos, custos, impactos positivos e negativos gerados em torno da operação das unidades, infraestrutura necessária e barreiras para a implantação. 

é apresentada na tabela 2.

Tabela 2. Unidades de produção na associação

\begin{tabular}{|c|c|c|c|c|c|}
\hline \multirow{2}{*}{$\begin{array}{c}\text { Solução } \\
\text { Proposta } \\
\end{array}$} & \multirow{2}{*}{ Infraestrutura } & \multicolumn{2}{|l|}{ Impactos } & \multirow[t]{2}{*}{ Barreiras } & \multirow[t]{2}{*}{ Custo } \\
\hline & & Positivo & Negativo & & \\
\hline $\begin{array}{l}\text { Unidade de } \\
\text { produção de } \\
\text { pias, tanques, } \\
\text { lavanderias e } \\
\text { tanquinhos }\end{array}$ & \begin{tabular}{|l|} 
a. Aquisiçãa do espaço para instalação da \\
unidade; (5) \\
b. Aquisição de betoneira para produção; \\
(5) \\
c. Contratação de funcionários para operar \\
a produção; (5) \\
d. Aquisição dos EPI's necessários para os \\
funcionários que irão operar as fábricas; (2) \\
e. Aquisição dos moldes para produção; (4) \\
f. Aquisição dos equipamentos para 0 \\
manuseio dos funcionários; (2) \\
Média = 3,83
\end{tabular} & $\begin{array}{l}\text { a. Geração de emprego e } \\
\text { renda para a região; }(0) \\
\text { b. Promover socialmente a } \\
\text { iniciativa; }(0) \\
\text { c. Reaproveitar os materiais } \\
\text { remanescentes; }(0) \\
\text { d. Retorno financeiro com a } \\
\text { produção; }(0) \\
\text { Média = } 0\end{array}$ & \begin{tabular}{|l|} 
a. Investimento para criação \\
das unidades produtivas; \\
(5) \\
b. Retorno a médio prazo; \\
(3) \\
c. Não ter retorno \\
financeiro; (2) \\
d. Competitividade com \\
outros produtos da mesma \\
linha; (2) \\
Média = 3
\end{tabular} & $\begin{array}{l}\text { a. Não ter demanda do material } \\
\text { produzido; (5) } \\
\text { b. Distância dos polos consumidores } \\
\text { do material; (5) } \\
\text { c. Demora com a disponibilização da } \\
\text { matéria-prima; (5) } \\
\text { d. Mudança de cultura dos } \\
\text { consumidores; (5) } \\
\text { e. Desinteresse no reaproveitamento } \\
\text { do material; (4) } \\
\text { Média }=\mathbf{4 , 8}\end{array}$ & $\begin{array}{l}\text { a. Frete com a movimentação } \\
\text { dos estoques remanescentes; } \\
\text { (2) } \\
\text { b. Funcionários; (5) } \\
\text { c. Operaçãa das unidades o } \\
\text { produtivas; (5) } \\
\text { d. Custo com manutenção; (3) } \\
\text { e. EPI's dos funcionários; (2) } \\
\text { f. Espaço para a instalaçấo da } \\
\text { unidade; (4) } \\
\text { g. Custo com a energia; (2) } \\
\text { Média }=\mathbf{2 , 8 5} \\
\text { Total }=\mathbf{1 4 , 4 8}\end{array}$ \\
\hline $\begin{array}{l}\text { Unidade de } \\
\text { produçãa de } \\
\text { tijolos e telhas } \\
\text { prensadas }\end{array}$ & \begin{tabular}{|l|} 
a. Aquisição do espaço para instalação da \\
unidade; (5) \\
b. Aquisição de betoneira para produção; \\
(5) \\
c. Contratação de funcionários para operar \\
a produção; (5) \\
d. Aquisição dos EPI's necessários para os \\
funcionários que irão operar as fábricas; (2) \\
e. Aquisiçãa dos moldes para produção; (3) \\
f. Aquisiçẫo dos equipamentos para o \\
manuseio dos funcionários; (2) \\
Média = 3,6
\end{tabular} & $\begin{array}{l}\text { a. Geração de emprego e } \\
\text { renda para a região; }(0) \\
\text { b. Promover socialmente a } \\
\text { iniciativa; }(0) \\
\text { c. Reaproveitar os materiais } \\
\text { remanescentes; }(0) \\
\text { d. Retorno financeiro com a } \\
\text { produção; }(0) \\
\text { Média }=0\end{array}$ & \begin{tabular}{|l|} 
a. Investimento para criação \\
das unidades produtivas; \\
(5) \\
b. Retorno a médio prazo; \\
(3) \\
c. Não ter retorno \\
financeiro; (2) \\
e. Competitividade com \\
outros produtos da mesma \\
linha; (2) \\
Média = 3
\end{tabular} & \begin{tabular}{|l|} 
a. Não ter demanda do material \\
produzido; (5) \\
b. Distância dos polos consumidores \\
do material; (5) \\
c. Demora com a disponibilização da \\
matéria-prima; (5) \\
d. Mudança de cultura dos \\
consumidores; (5) \\
e. Desinteresse no reaproveitamento \\
do material; (4) \\
Média $=4,8$
\end{tabular} & $\begin{array}{l}\text { a. Frete com a movimentação } \\
\text { dos estoques remanescentes; } \\
\text { (2) } \\
\text { b. Funcionários; (5) } \\
\text { c. Operaçãa das unidades o } \\
\text { produtivas; (5) } \\
\text { d. Custo com manutençãa; (3) } \\
\text { e. EPI's dos funcionários; (2) } \\
\text { f. Espaço para a instalação da } \\
\text { unidade; (4) } \\
\text { g. Custo com a energia; (2) } \\
\text { Média }=\mathbf{3 , 2} \\
\text { Total =14.6 }\end{array}$ \\
\hline $\begin{array}{l}\text { Área de } \\
\text { produção de } \\
\text { pedra } \\
\text { portuguesa }\end{array}$ & $\begin{array}{l}\text { a. Aquisição do espaço para instalação da } \\
\text { unidade; (5) } \\
\text { b. Aquisição de betoneira para produção; } \\
\text { (0) } \\
\text { c. Contratação de funcionários para operar } \\
\text { a produção; (5) } \\
\text { d. Aquisição dos EPI's necessários para os } \\
\text { funcionários que irão operar as fábricas; (2) } \\
\text { e. Aquisição dos moldes para produção; (3) } \\
\text { f. Aquisição dos equipamentos para 0 } \\
\text { manuseio dos funcionários; (4) } \\
\text { Média = 3,16 }\end{array}$ & $\begin{array}{l}\text { a. Geração de emprego e } \\
\text { renda para a região; }(0) \\
\text { b. Promover socialmente a } \\
\text { iniciativa; }(0) \\
\text { c. Reaproveitar os materiais } \\
\text { remanescentes; }(0) \\
\text { d. Retorno financeiro com a } \\
\text { produção; }(0) \\
\text { Média = } 0\end{array}$ & $\begin{array}{l}\text { a. Investimento para criação } \\
\text { das unidades produtivas; } \\
\text { (5) } \\
\text { b. Retorno a médio prazo; } \\
\text { (3) } \\
\text { c. Não ter retorno } \\
\text { financeiro; (5) } \\
\text { e. Competitividade com } \\
\text { outros produtos da mesma } \\
\text { linha; (1) } \\
\text { Média }=3,5\end{array}$ & $\begin{array}{l}\text { a. Não ter demanda do material } \\
\text { produzido; (5) } \\
\text { b. Distância dos polos consumidores } \\
\text { do material; (3) } \\
\text { c. Demora com a disponibilização da } \\
\text { matéria-prima; (5) } \\
\text { d. Mudança de cultura dos } \\
\text { consumidores; (5) } \\
\text { e. Desinteresse no reaproveitamento } \\
\text { do material; (4) } \\
\text { Média = 4,4 }\end{array}$ & $\begin{array}{l}\text { a. Frete com a movimentação } \\
\text { dos estoques remanescentes; } \\
\text { (3) } \\
\text { b. Funcionários; (5) } \\
\text { c. Operação das unidades o } \\
\text { produtivas; (3) } \\
\text { d. Custo com manutenção; (3) } \\
\text { e. EPI's dos funcionários; (3) } \\
\text { f. Espaço para a instalaçẫo da } \\
\text { unidade; (2) } \\
\text { g. Custo com a energia; (1) } \\
\text { Média = 2,85 } \\
\text { Total =13,91 }\end{array}$ \\
\hline $\begin{array}{l}\text { Unidade de } \\
\text { produção de } \\
\text { tijolos } \\
\text { intertravados }\end{array}$ & $\begin{array}{l}\text { a. Aquisição do espaço para instalação da } \\
\text { unidade; (5) } \\
\text { b. Aquisiçãa de betoneira para produção; } \\
\text { (5) } \\
\text { c. Contratação de funcionários para operar } \\
\text { a produção; (5) } \\
\text { d. Aquisição dos EPI's necessários para os } \\
\text { funcionários que irão operar as fábricas; (2) } \\
\text { e. Aquisição dos moldes para produçãa; (5) } \\
\text { f. Aquisição dos equipamentos para o } \\
\text { manuseio dos funcionários; (2) }\end{array}$ & $\begin{array}{l}\text { a. Geração de emprego e } \\
\text { renda para a região; }(0) \\
\text { b. Promover socialmente a } \\
\text { iniciativa; }(0) \\
\text { c. Reaproveitar os materiais } \\
\text { remanescentes; }(0) \\
\text { d. Retomo financeiro com a } \\
\text { produção; }(0) \\
\text { Média = } 0\end{array}$ & $\begin{array}{l}\text { a. Investimento para criação } \\
\text { das unidades produtiva;(5) } \\
\text { b. Retomo a médio prazo; } \\
\text { (3) } \\
\text { c. Não ter retorno } \\
\text { financeiro; (5) } \\
\text { d. Competitividade com } \\
\text { outros produtos da mesma } \\
\text { linha; (1) } \\
\text { Média }=3,5\end{array}$ & $\begin{array}{l}\text { a. Não ter demanda do material } \\
\text { produzido; (5) } \\
\text { b. Distância dos polos consumidores } \\
\text { do material; (4) } \\
\text { d. Demora com a disponibilização da } \\
\text { matéria-prima; (5) } \\
\text { e. Mudança de cultura dos } \\
\text { consumidores; (5) } \\
\text { f. Desinteresse no reaproveitamento } \\
\text { do material; (4) } \\
\text { Média }=4,6\end{array}$ & $\begin{array}{l}\text { a. Frete com a movimentação } \\
\text { dos estoques remanescentes; } \\
\text { (3) } \\
\text { b. Funcionários; (5) } \\
\text { c. Operação das unidades o } \\
\text { produtivas; (4) } \\
\text { d. Custo com manutenção; (3) } \\
\text { e. EPI's dos funcionários; (3) } \\
\text { f. Espaço para a instalaçẫo da } \\
\text { unidade; (3) } \\
\text { g. Custo com a energia; (2) } \\
\text { Média }=\mathbf{3 , 2 8} \\
\text { Total }=\mathbf{1 5 , 3 8}\end{array}$ \\
\hline $\begin{array}{l}\text { Area de } \\
\text { confecç̃ão de } \\
\text { artesanato }\end{array}$ & \begin{tabular}{|l|} 
a. Aquisição do espaço para instalação da \\
unidade; (5) \\
b. Aquisição de betoneira para produção; \\
(0) \\
c. Contratação de funcionários para operar \\
a produçãã; (2) \\
d. Aquisição dos EPI's necessários para os \\
funcionários que irão operar as fábricas; (2) \\
e. Aquisição dos moldes para produção; (0) \\
f. Aquisição dos equipamentos para o \\
manuseio dos funcionários; (3) \\
Média = 2
\end{tabular} & $\begin{array}{l}\text { a. Geração de emprego e } \\
\text { renda para a regiẫo; (0) } \\
\text { b. Promover socialmente a } \\
\text { iniciativa; }(0) \\
\text { c. Reaproveitar os materiais } \\
\text { remanescentes; }(0) \\
\text { d. Retorno financeiro com a } \\
\text { produção; }(0) \\
\text { Média }=0\end{array}$ & \begin{tabular}{|l|} 
a. Investimento para criação \\
das unidades produtivas;(3) \\
b. Retorno a médio prazo; \\
(5) \\
c. Não ter retorno \\
financeiro; (5) \\
d. Competitividade com \\
outros produtos da mesma \\
linha; (0) \\
Média $=3,25$
\end{tabular} & $\begin{array}{l}\text { a. Não ter demanda do material } \\
\text { produzido; }(0) \\
\text { b. Distância dos polos consumidores } \\
\text { do material; }(0) \\
\text { c. Demora com a disponibilização da } \\
\text { matéria-prima; ( } 0 \text { ) } \\
\text { d. Mudança de cultura dos } \\
\text { consumidores; (2) } \\
\text { e. Desinteresse no reaproveitamento } \\
\text { do material; (5) } \\
\text { Média = 1,4 }\end{array}$ & $\begin{array}{l}\text { a. Frete com a movimentação } \\
\text { dos estoques remanescentes; } \\
\text { (1) } \\
\text { b. Funcionários; (1) } \\
\text { c. Operaçã̃o das unidades o } \\
\text { produtivas; (2) } \\
\text { d. Custo com manutenção; (3) } \\
\text { e. EPI's dos funcionários; (1) } \\
\text { f. Espaço para a instalaçẫo da } \\
\text { unidade; (2) } \\
\text { g. Custo com a energia; (2) } \\
\text { Média }=1,714 \\
\text { Total }=8,36 \\
\end{array}$ \\
\hline
\end{tabular}

Fonte: Autor, 2019

Com a tabela desenvolvida, foram atribuídas as notas referentes às resistências aos processos para definir as unidades produtivas que geram o menor impacto negativo ou que tem o menor custo, destas unidades produtivas, foram analisadas as mais viáveis para a aplicação da rota tecnológica. Essa análise pode 
ser também adaptada conforme a demanda das regiões e em detrimento da entrada de novos produtos e novas unidades produtivas nas distintas regiões.

Tabela 03 - Matriz de resistência encontrada

\begin{tabular}{|l|c|c|c|c|c|c|}
\hline \multicolumn{1}{|c|}{ Matriz de Impacto } & \multicolumn{1}{|c|}{$\begin{array}{l}\text { Impacto } \\
\text { Sositivo }\end{array}$} & $\begin{array}{c}\text { Impacto } \\
\text { Negativo }\end{array}$ & Infra. & Barreira & Custo & Total \\
\hline 1 - Produção de pias e tanques & 0 & 3 & 3,83 & 4,8 & 2,85 & $\mathbf{1 4 , 4 8}$ \\
\hline 2 - Produção de artesanato & 0 & 3,25 & 2 & 1,4 & 1,71 & $\mathbf{8 , 3 6}$ \\
\hline 3 - Produção de pedra portuguesa & 0 & 3,5 & 3,16 & 4,4 & 2,85 & $\mathbf{1 3 , 9 1}$ \\
\hline 4 - Produção de piso intertravado & 0 & 3,5 & 4 & 4,6 & 3,28 & $\mathbf{1 5 , 3 8}$ \\
\hline 5 - Produção de Tijolo e telhas prensadas & 0 & 3 & 3,6 & 4,8 & 3,2 & $\mathbf{1 4 , 6}$ \\
\hline
\end{tabular}

Fonte: Autor, 2019

As soluções que oferecem os menores índices tendem a ser os de maior facilidade de implantação, embora a diferença entre as unidades produtivas seja baixa, a rota marcada em verde é a rota em que não há grande necessidade de investimento, pois será uma unidade produtiva de cunho social, para o desenvolvimento da população local, oficina de artesanato e cursos para a fabricação de ornamentos. Todas apresentaram um bom potencial de aplicação e baixa resistência à realidade das empresas locais.

Cada empresa pode aplicar uma nova estruturação da lógica das resistências aos fluxos (Donato \& PASSOS, 2014 [7]) para a aplicação das unidades produtivas com suas próprias variáveis e definir as unidades mais viáveis dentro da empresa de reaproveitamento.

\section{CONCLUSÃO}

O estudo atendeu ao objetivo proposto, pois demonstrou que a definição de uma rota tecnológica, após a aplicação da análise das resistência aos fluxos associada a metodologia Fuzzy contribui para a implementação de uma iniciativa para o funcionamento de economia circular a partir do reaproveitamento de rejeitos de rocha ornamentais, abrindo a oportunidade para a criação de novos empregos, diversificação na geração de novos materiais e redução dos impactos ambientais por meio da limpeza, a longo prazo, das pedreiras de rocha ornamental que funcionam a mais de 50 anos que nunca tiveram os seus rejeitos devidamente explorados e retrabalhados, trazendo uma nova consciência socioambiental para as regiões produtoras de rocha ornamental.

O fluxo que envolve a economia circular é perfeitamente aplicado nesse processo, pois são reaproveitados materiais resultantes dos processos de extração (provenientes da pedreiras) e manufatura (beneficiamentos) da matéria prima, os objetos que não foram aproveitados serão aplicados nas etapas de reuso, reparo, transformação e redistribuição, para ser remanufaturados, produzindo novos materiais para outros processos, ou novos bens de consumo para a comercialização. Utilizando 
está abordagem para o conceito de economia circular, onde foi aplicado nas etapas de extração e beneficiamento.

A aplicação do roadmap, a metodologia da análise das resistências e da lógica Fuzzy (Nicoleti, 2006 [8]) foi fundamental para o desenvolvimento da rota tecnológica e as soluções propostas, e permitiram detalhar os processos, garantindo a avaliação prévia do estudo e das etapas dos processos, desde o funcionamento da associação que realizará a gestão do reaproveitamento e das aplicações nas unidades produtivas propostas.

Para o funcionamento dessa rota tecnológica seria também interessante incentivos governamentais para as empresas que disponibilizarão as matérias primas para a associação que irá realizar o processo de fragmentação das rochas nas centrais de processamento, incentivado com redução de impostos, incentivos fiscais etc. Visando manter as empresas motivadas e comprometidas com reaproveitamento dos materiais e desenvolvimento social e econômico das regiões envolvidas no estudo.

\section{REFERÊNCIAS}

1 APOLINÁRIO, E.A.; SANTOS, G.R. S.; RIBEIRO, D. V. Efeitos da adição do resíduo de corte de mármore e granito (RCMG) nas propriedades das argamassas de cimento portland e industrializada no estado aplicado. IX Fórum Ambiental da Alta Paulista, v. 9, n. 1, p. 123-140, 2013.

${ }^{2}$ MOURA, W.; GONÇALVES, J.; LEITE, R. S. Utilização do resíduo de corte de mármore e granito em argamassas de revestimentos e confecção das lajotas para piso. Sitientibus, n. 26, p. 49-61, jan./jun. 2002.

${ }^{3}$ Lacy, P. Gaining an Edge from the Circle: Growth, Innovation and Customer Value through the Circular Economy. Accenture Strategy. 2015

${ }^{4}$ Stahel, W. R. (1982). The product-life factor. In S. G. Orr (Ed.), An inquiry into the nature of sustainable societies. The role of the private sector. HARC Houston, TX: The Mitchell Prizes 1982.

${ }^{5}$ PHAAL, R.; FARRUKH, C. J. P.; PROBERT, D. R. Customizing Roadmapping. Research Technology Management, v. 47, n. 2, p. 26-37, 2004b

${ }^{6}$ PHAAL R; MULLER G. An architectural framework for roadmapping: towards visual strategy. Technological Forecasting \& Social Change 76:39-49. 2009.

7 DONATO V.; PASSOS F. U. Proposta e aplicação de um método, baseado no contexto das linhas de transporte de menor resistência, para qualificar cadeias logísticas de distribuição como uma cadeia verde. RECC - Revista Eletrônica Científica do CRA-PR, v. 2, n. 2, p. 47-61, 2014.

${ }^{8} \mathrm{NICOLETI}, \mathrm{M}$. Do Carmo. Fundamentos da teoria de conjuntos Fuzzy. Editora Edufscar. Santa Catarina. 2006. 